原 著

\title{
自律神経活動の概日リズムよりみた拡張型心筋症の 検討
}

斎藤靖浩*

拡張型心筋症 (DCM) 患者のホルター心電図記録から心拍変動解析を行つた. 得られた LF · HFに Mem Calc システムを用いた最小2 乗フィッティングを行い, 周期, 振幅, 頂点位相, 水準値の日内変動指標を求め, 病態との関連を評価した. 結果：(1)DCMでは，健常対照群に比しHF · LFの $24 \pm 4$ 時間周期の消失例や頂 点位相の異常を示す例が有意に多かつた. (2) DCMでは, 対照群に比しHF・LFの 水準值が有意に低く, HF の振幅が有意に小であつた. (3)多変量解析によるVTの有 無の検討で, HFの頂点位相の昼間帯移行に関連があつた. (4)DCM の死亡群は, 生存群に比しLFの水準值は有意に低かつた.Coxの比例ハッザード回帰による心 臓死に対する予後予測で，LFの rhythm 異常が有意に心臓死と関連があつた．以上 より LF · HF の日内変動指標が, DCM のVT 発生や予後予測の指標となる可能性 が考えられた。

(心電図 19 ：No.6, 694 700, 1999)

I.はじめに

急性心筋梗塞の発症 ${ }^{1,2}$, や心臓突然死の発生 ${ }^{3)} に$ は，1日のうちで多い時間帯があることが指摘され ている.この現象を自律神経活動の概日リズムで説 明する報告がある ${ }^{4), 5)}$. 特に冠動脈疾患患者におけ

\begin{tabular}{|ll|}
\hline Key Words & ・心拍変動 \\
& ・概日リズム \\
& •拡張型心筋症 \\
\hline
\end{tabular}

*川崎医科大学内科循環器部門

（７01-0192 岡山県倉敷市松島 577）
る副交感神経活動の概日リズムの異常が報告され， その臨床的意義に興味がもたれている.

生体リズムの中で代表的なものに 24 時間リズムが あり，これを概日リズムと呼ぶ. Halbergが考案し た最適余弦曲線6)では（図1），24時間を 1 周期とし て, 現象のピークの時間を頂点位相 (acrophase), その平均を水準值 (MESOR), 変動の幅を振幅 (amplitude) としている。

虚血性心疾患を基礎疾患とする心不全例では，心 拍変動の低下例で予後が悪いと報告されているが, 拡張型心筋症（DCM）での概日リズムについては

Circadian rhythm of heart rate variability in dilated cardiomyopathy. Yasuhiro Saitou 
十分には解明されていない。そこで，DCMにおけ る心拍変動 LF・HFの概日リズムを検討し, 病態と の関連を評価した。

\section{II. 方 法}

対象はNYHA II 〜 III 度の正常洞調律の DCM30例 (平均 $47 \pm 15$ 歳) と control として心疾患のない入院 患者 30 例（平均 $47 \pm 12$ 歳）である（表 1). 本症診 断は, 昭和 57 年度厚生省特定疾患特発性心筋症研究 班の基準7に基づいた。

方法は, DCMの診断治療のための初回入院の初 期に記録した 24 時間ホルター心電図の RR 間隔を

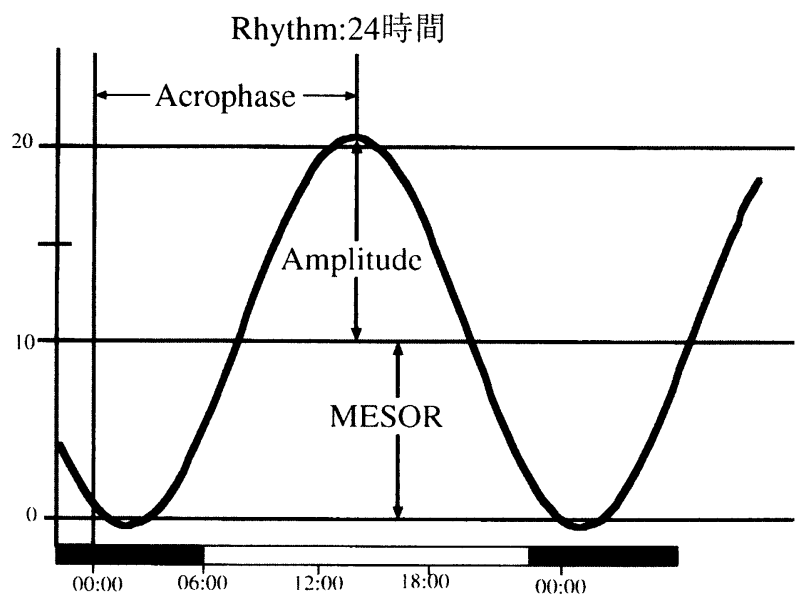

図1 Halberg が考案した最適余弦曲線
Marquette社製 HRV software002A を用いてFFT解 析し，48分間の LF $(0.04 \sim 0.15 \mathrm{~Hz})$ と HF $(0.15 \sim$ $0.4 \mathrm{~Hz}$ ）を測定．得られた全 30 区間の $\mathrm{LF} ・ \mathrm{HF}$ に Mem Calc システムを用いた最小 2 乗フィッティン グを行い, 周期 (rhythm), 振幅 (amplitude), 頂 点位相 (acrophase), 水準值 (MESOR) の日内変 動指標を求めた。なおホルター心電図を記録する 3 日前からは，可能な限り薬剤の服用を中止した.

検討項目は,

1. DCM群と control群の比較

2. DCM群内での比較

$$
\begin{aligned}
& \text { 1) 心室頻拍（VT）の有無 } \\
& \text { 2）生存例と死亡例 }
\end{aligned}
$$

心室頻拍（+）とは心室性期外収縮 5 連発以上ホル ター心電図で記録された例とした。なお，DCMの 平均経過観察期間は, $25.9 \pm 7.5$ カ月であった.

検討指標は rhythm, acrophase, amplitude, MESORである. rhythmは $24 \pm 4$ 時間を正常とし, acrophase は 23 時から 6 時の夜間帯を正常とした。 統計学的処理は, non-paired t test, $\chi^{2}$ test, 多変量 解析（Coxの比例ハッザード回帰, 多重ロジスティ ック回帰）を使用した.すべてのデータは, 平均士 標準偏差で表し, $\mathrm{p}<0.05$ をもって有意とした。

表1 背景因子

\begin{tabular}{|l|ccc|}
\hline & $\begin{array}{c}\text { DCM total } \\
(\mathrm{n}=30)\end{array}$ & $\begin{array}{c}\text { DCM 生存群 } \\
(\mathrm{n}=23)\end{array}$ & $\begin{array}{c}\text { DCM死亡群 } \\
(\mathrm{n}=7)\end{array}$ \\
\hline 年齢 (歳) & $47 \pm 15$ & $51 \pm 13$ & $34 \pm 16$ \\
NYHA(例) & & & \\
$\quad$ II & 22 & 17 & 5 \\
III & 8 & 6 & 2 \\
収縮期血圧(mmHg) & $115 \pm 11$ & $116 \pm 12$ & $111 \pm 5$ \\
心拍数 (/分) & $74 \pm 10$ & $74 \pm 10$ & $73 \pm 10$ \\
左室駆出率(\%) & $28 \pm 7$ & $29 \pm 7$ & $25 \pm 7$ \\
心胸比(\%) & $57.2 \pm 4.8$ & $56.9 \pm 4.8$ & $57.9 \pm 4.9$ \\
薬(例) & & & \\
ジギタリス & 5 & 3 & 2 \\
ACE阻害薬 & 3 & 2 & 1 \\
$\beta$ フブッカー & 0 & 0 & 0 \\
\hline
\end{tabular}


表2 HF·LFの日内変動指標による DCM 群と control群の比較

HF

\begin{tabular}{|l|c|c|c|c|}
\hline & $\begin{array}{c}\text { MESOR } \\
\ln \left(\mathrm{msec}^{2}\right)\end{array}$ & $\begin{array}{c}\text { Amplitude } \\
\ln \left(\mathrm{msec}^{2}\right)\end{array}$ & $\begin{array}{c}\text { Rhythm異常 } \\
\text { (例) }\end{array}$ & $\begin{array}{c}\text { Acrophase異常 } \\
\text { (例) }\end{array}$ \\
\hline control(30例) & $4.66 \pm 0.83$ & $0.81 \pm 0.37$ & 1 & 2 \\
\hline $\mathrm{DCM}(30$ 例) & $3.73 \pm 1.08$ & $0.61 \pm 0.39$ & 8 & 16 \\
\hline & $\mathrm{p}<0.01$ & $\mathrm{p}<0.05$ & $\mathrm{p}<0.05$ & $\mathrm{p}<0.01$ \\
\hline
\end{tabular}

LF

\begin{tabular}{|l|c|c|c|c|}
\hline & $\begin{array}{c}\text { MESOR } \\
\ln \left(\mathrm{msec}^{2}\right)\end{array}$ & $\begin{array}{c}\text { Amplitude } \\
\ln \left(\mathrm{msec}^{2}\right)\end{array}$ & $\begin{array}{c}\text { Rhythm異常 } \\
\text { (例) }\end{array}$ & $\begin{array}{c}\text { Acrophase異常 } \\
\text { (例) }\end{array}$ \\
\hline control(30例) & $5.67 \pm 0.69$ & $0.56 \pm 0.25$ & 3 & 2 \\
\hline $\mathrm{DCM}(30$ 例) & $4.46 \pm 1.13$ & $0.50 \pm 0.27$ & 11 & 14 \\
\hline & $\mathrm{p}<0.01$ & $\mathrm{NS}$ & $\mathrm{p}<0.05$ & $\mathrm{p}<0.01$ \\
\hline
\end{tabular}

HF-Amplitude

HF-MESOR

HF-Acrophase
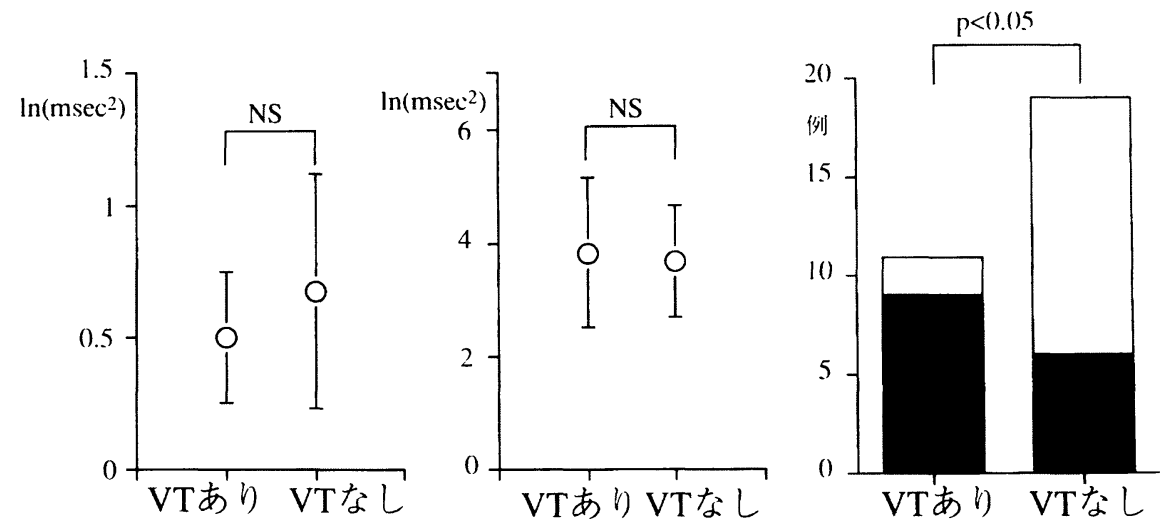

Acrophase異常あり

Acrophase異常なし

図2 DCMでVTの有無によるHFの検討

\section{III. 結 果}

\section{DCM 群と control 群の比較（表2）}

$\mathrm{HF}$ の検討：MESORは, DCM 群（平均 $3.73 \pm$ $\left.1.08 \ln (\mathrm{msec})^{2}\right)$ では control 群 $\left(4.66 \pm 0.83 \ln (\mathrm{msec})^{2}\right)$ に比して有意に低值 $(\mathrm{p}<0.01)$, amplitudeはDCM 群 $\left(\right.$ 平均 $\left.0.61 \pm 0.391 \mathrm{n}(\mathrm{msec})^{2}\right)$ では control 群 $\left(0.81 \pm 0.37 \ln (\mathrm{msec})^{2}\right)$ に比して有意に小 $(\mathrm{p}<0.05)$ であった。 rhythm 異常は, DCM 群（30例中 8例） が control 群（30 例中 1 例）に比して有意に多く 696 （p<0.05）, acrophase 異常は DCM群（30例中 16例） がcontrol群（30例中2例）に比して有意に多く認め られた $(\mathrm{p}<0.01)$.

LFの検討：MESORはDCM群（平均 $4.46 \pm 1.13 \mathrm{ln}$ $\left.(\mathrm{msec})^{2}\right)$ では control 群 $\left(5.67 \pm 0.69 \mathrm{ln}(\mathrm{msec})^{2}\right)$ に 比して，有意に低值（ $\mathrm{p}<0.01 ）$, amplitude は両者 に差はなかった。 rhythm異常は，DCM群（30例中 11例）がcontrol群（30例中3例）に比して有意に多 く（p<0.05）, acrophase 異常はDCM群（30例中 14 例）がcontrol群（30例中2例）に比して有意に多 
表3多重ロジスティック回帰によるVT の検討

回帰係数とその有意性

有効デー夕数 $=30$

\begin{tabular}{|ccrccc|}
\hline 次数 & 変数名 & 係数 & $\begin{array}{c}\text { 係数 } / \\
\text { 標準誤差 }\end{array}$ & Z值 & $\mathrm{P}$ \\
& & & & & \\
0 & & 7.067 & 5.583 & 1.266 & 0.205 \\
1 & 年齢 & 0.056 & 0.036 & 1.540 & 0.124 \\
2 & HF -Acrophase(例) & 2.287 & 1.153 & 1.983 & 0.047 \\
3 & 収縮期血圧 $(\mathrm{mmHg})$ & -0.106 & 0.057 & 1.866 & 0.062 \\
\hline
\end{tabular}

HF-MESOR

HF-Acrophase

HF-Rhythm
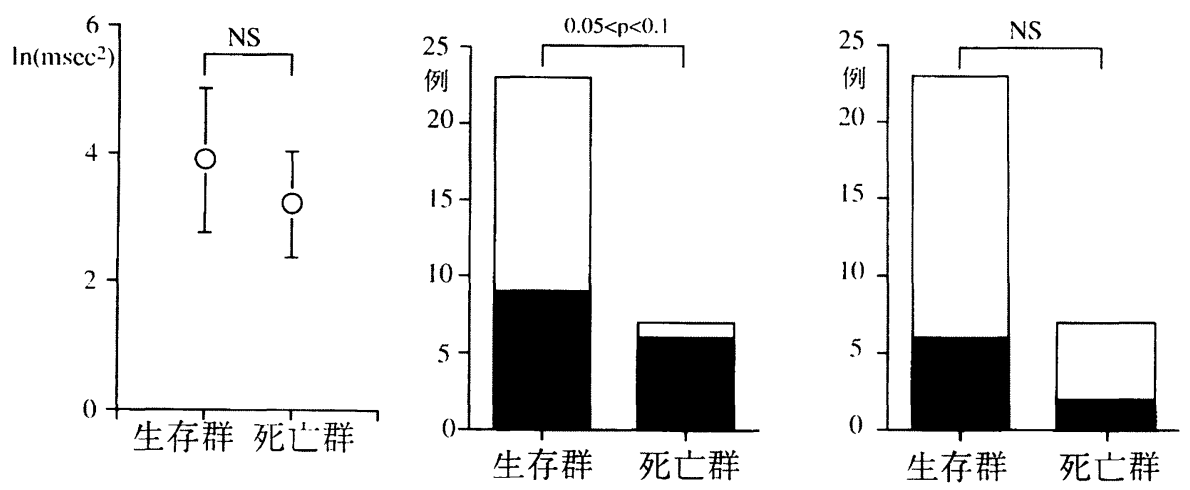

Acrophase異常あり $\square$ Acrophase異常なし

ロリズム異常あり

ロリズム異常なし

図3 DCMの生存群と死亡群による HFの日内変動指標の検討

かった（p<0.01）.

\section{DCM群内でVTの有無による検討}

DCM30例中 11 例にVTを認めた。VTの有無で分 けた2群間でHFの MESOR, amplitudeに差はなかっ た、しかし，VTを有する群はVTのない群に比し て, acrophase が昼間帯に移動する例が有意に多か った（11例中 9例 vs19例中6例：p<0.05）（図2）.

さらにVT発生の関与している因子を多重ロジス ティック回帰すると, HFの acrophaseが昼間帯に移 動する例がVTと有意に関連が認められた（表3）.

3. 拡張型心筋症のうち生存例と死亡例による検討 経過観察期間中に, DCM 30 例中 7 例が死亡した (5例が心不全死, 2 例が突然死). 死亡群と生存群の 間にHFの MESOR, amplitudeに差はなかった。し かし死亡群は生存群に比して, acrophaseが昼間帯
に移動する例が多い傾向であった（7例中 6 例 vs 23 例中 9 例 $: 0.05<\mathrm{p}<0.1$ ) (図3).

LFの MESOR は死亡群 (平均 $3.71 \pm 1.21 \ln (\mathrm{msec})^{2}$ ) では生存群 $\left(4.69 \pm 1.04 \mathrm{ln}(\mathrm{msec})^{2}\right)$ に比し，有意に 小（p<0.05）, amplitudeは両者に差はなかった. rhythm 異常は, 死亡群（7例中5例）が生存群（23 例中 6例）に比して多い傾向にあった $(0.05<p<$ 0.1）（図4）。また， time domain 指標である SDNN は，両群間に差はなかった [死亡群（平均 $78.4 \pm$ $34.6 \mathrm{msec})$ vs生存群 $(98.5 \pm 40.7 \mathrm{msec})]$.

次にCox の比例ハッザード回州により心蔵死に対 する予後予測を行った（表4）. 左室駆出率には関連 が認められなかったが，LFの rhythm 異常が有意に 心臓死と関連があった.

症例呈示：図5にcontrol群（47歳）の1例を示す。 


\section{LF-Amplitude}

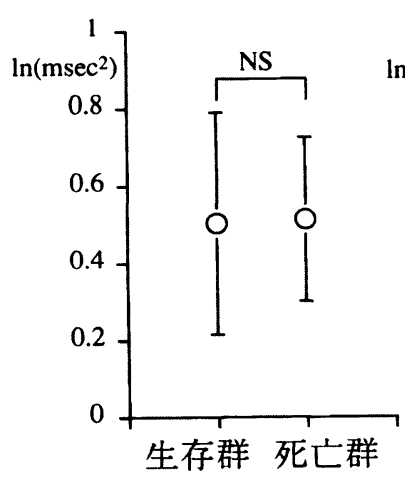

LF-MESOR

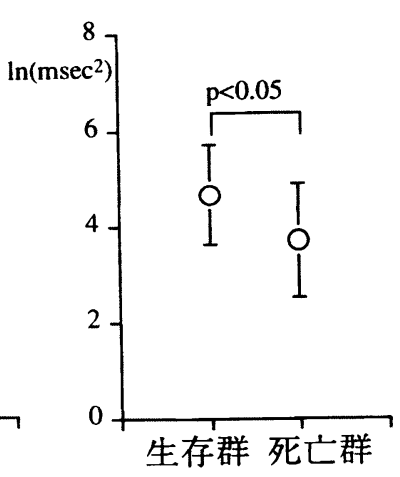

\section{LF-Rhythm}

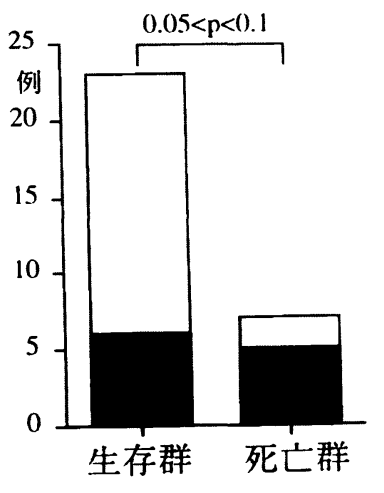

リズム異常あり

リズム異常なし

図4 DCMの生存例と死亡例による LFの日内変動指標の検討

表4 Coxの比例ハッザード回帰による心蔵死に対する予後予測

回帰係数の推定值

有効デー夕数 $=30$

\begin{tabular}{|cccccc|}
\hline 次数 & 変数名 & 係数 & $\begin{array}{c}\text { 係数 } / \text { 標準誤差 } \\
\text { ～}\end{array}$ & Z值 & $\mathrm{P}$ \\
\hline 0 & 年齢 & -0.064 & 0.036 & 1.749 & 0.08 \\
1 & LF-Rhythm (例) & 3.359 & 1.623 & 2.069 & 0.038 \\
2 & 心胸比(\%) & 0.254 & 0.135 & 1.875 & 0.061 \\
3 & 左室駆出率(\%) & -0.086 & 0.090 & 0.962 & 0.336 \\
\hline
\end{tabular}

HF・LFともにMESOR, amplitudeは正常で, acrophase が夜間帯（23 時から6時）にあり，24時 間周期の明瞭な概日リズムを示している. 図6に DCM（47歳）の男性例を示す. HF・LFの MESOR と amplitudeが著明に低下し， acrophaseの 昼間帯移動がみられる．本例ではVTが記録され，1 年後に突然死した。

\section{IV. 考案}

慢性心不全における自律神経障害は, 動脈圧受容 体反射の障害 ${ }^{8)}$ や心拍変動の異常 ${ }^{9)}$ をとに指摘さ れている.jっ血性心不全患者の予後予測に，自律 神経活動の評価が有用であったという報告 ${ }^{10) ~ 12) ~ も ~}$ ある．DCMは，しばしばうっ血性心不全，心室性
不整脈や突然死を生じるため, さまざまな方法で危 険因子の検討が行われている ${ }^{13) ~ 16) . ~}$

本研究で示したように, DCMでは夜間の HFが低 下し自律神経活動の昼-夜リズムの異常例が多く認め られた. HFはMESORの低下のみならず, amplitude の低下もみられた.これは本症における, 内的・外 的刺激に対する副交感神経反射の低下と考えられ た. 副交感神経の抗不整脈作用は反射性興奮作用が 重要とされ 17), これら HF の日内変動指標の異常例 は, 循環動態の急激な変化時に心事故を生じやすい 状態にあると推察された。

一方 LF は，圧受容体反射を反映した血管運動性 交感神経機能を表現し ${ }^{18)}, \mathrm{LF}$ 值の低下は心拍出量減 少や総血管抵抗上昇と相関する ${ }^{19)}$ とされている．心 
$\mathrm{HF}$

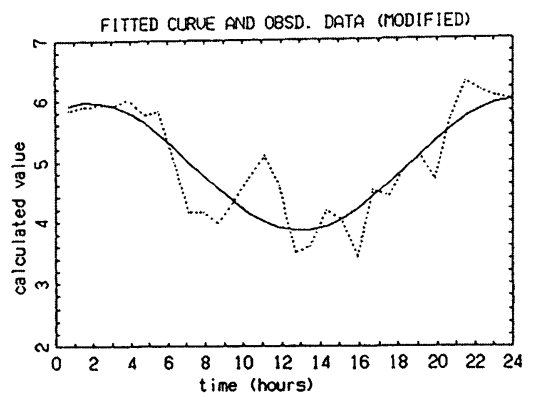

MSOR

Amplitude 1.05

Rhythm 22.3

Acrophase 1.8

LF

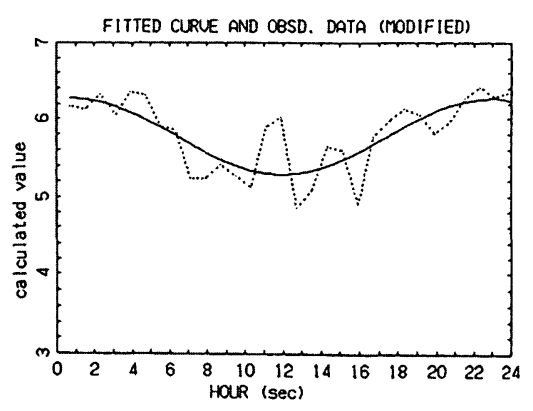

MSOR $\quad 5.77$

Amplitude 0.49

Rhythm 22.1

Acrophase 0.85
HF

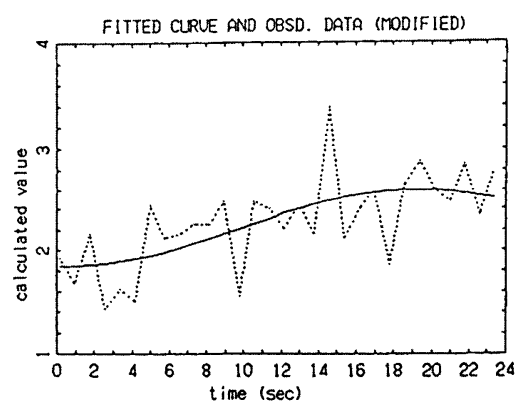

MSOR

Amplitude $\quad 0.37$

Rhythm $\quad 37.1$

Acrophase $\quad 19.2$
LF

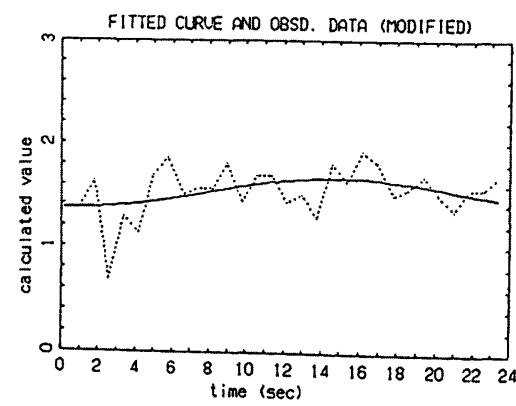

MSOR $\quad 1.52$

Amplitude 0.15

Rhythm $\quad 27.4$

Acrophase 14.7

図5 Control (47歳) の1例

不全の予後予測においてLF低下は，心不全死との

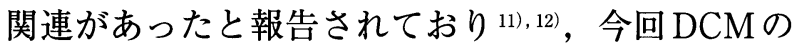
死亡例でLFのMESORの低下と合致していた。

我々は，心不全患者でLFの概日リズムの消失し た例の突然死を報告している ${ }^{20)}$ ささらに今回行った Coxの比例ハッザード回帰による心臓死に対する予 後予測で, 従来の指標である左室駆出率 ${ }^{21)}$, 心胸比 ${ }^{22)}$ などよりも LFの概日リズムの消失に関連が認めら れ，LFのMESORの低下のみならず，概日リズムの 検討も重要であると考えられた。

心不全例における自律神経異常の研究では, 心不 全の基礎疾患に虚血性心疾患を含む報告 ${ }^{10)}$,11) や，検 討項目が time domainの HRV 指標である報告 ${ }^{12) ~ 14) ~}$ が多い。それらの報告では, time domain 指標の SDNNがDCMの予後予測で有用であると報告され ている ${ }^{12), 13)}$ ．しかし我々の検討ではSDNNでは予後 予測はできず，LFの水準值の低下や， HF・LFの 概日リズムの消失が有用と考えられた。また，VT

\section{図6 DCM（47歳）の男性例}

発生も多重ロジスティック回㷌により, HFの acrophaseが昼間帯に移動する例がVT と有意に関 連が認められ，24時間全体の HF・LFの絶対值だ けを検討するよりも，概日リズム指標を用いて検討 した方が，個々の症例を検討するには優れている可 能性があると考えられた。

今回の研究の問題点として, DCM症例が 30 例と 少なく経過観察期間が 25 カと短いため, 統計結果 が過大評価されている可能性があり，今後も検討を 重ねる必要があると思われる。

\section{V. 結語}

DCM 患者ではHF・LFの概日リズムの消失例や， 水準值・振幅の低下例を多く認めた。各指標が DCMのVT 発生や予後予測の指標となる可能性が考 えられた。

\section{謝 辞}

稿を終えるにあたり，御指導を賜った川崎医科大 
学生理学 辻岡克彦教授, 川崎医科大学内科循環器

部門 沢山俊民教授, 井上省三先生, 中央検査部 市原清志助教授に深甚なる謝意を表します。

\section{〔文献〕}

1 ) Muller JE, Ludmer PL, Willich SN, Tofler GH, Aylmer G, Klangos I, Stone PH: Circadian variation in the frequency of sudden cardiac death. Circulation 75: 131, 1987

2 ) Behar S, Halabi M, Reicher Reiss H, Zion M, Kaplinsky E, Mandelzweig L, Goldbourt U: Circadian variation and possible external triggers of onset of myocardial infarction. SPRINT Study Group. Am J Med 94: 395, 1993

3 ) Muller JE, Ludmer PL, Willich SN, Tofler GH, Aylmer G, Klangos I, Stone PH: Circadian variation in the frequency of sudden cardiac death. Circulation 75: 131, 1987

4) Hjalmarson A, Gilpin EA, Nicod P, Dittrich H, Henning H, Engler R, Blacky AR, Smith SC Jr, Ricou F, Ross J Jr: Differing circadian patterns of symptom onset in subgroups of patients with acute myocardial infarction. Circulation 80: 267, 1989

5 ) Kleiman NS, Schechtman KB, Young PM, Goodman DA, Boden WE, Pratt CM, Roberts R: Lack of diurnal variation in the onset of non- $Q$ wave infarction. Circulation 81: 548, 1990

6 ) Halberg F: Implications of biologic rhythms for clinical practice. Hosp Pract 12: 139, 1977

7 ) 厚生省特定疾患特発性心筋症調査研究班: 特発性心筋 症診断の手引き。昭和 57 年度報告集, 1983, 13

8 ) Barron HV, Lesh MD: Autonomic nervous system and sudden cardiac death. J Am Coll Cardiol 27: 1053, 1996

9 ) Kienzle MG, Ferguson DW, Birkett CL, Myers GA, Berg WJ, Mariano DJ: Clinical, hemodynamic and sympathetic neural correlates of heart rate variability in congestive heart failure. Am J Cardiol 69: 761, 1992

10) Ponikowski P, Anker SD, Chua TP, Szelemej R, Piepoli M; Adamopoulos S, Webb Peploe K, Harrington D, Banasiak W, Wrabec K, Coats AJ: Depressed heart rate variability as an independent predictor of death in chronic congestive heart failure secondary to ischemic or idiopathic dilated cardiomyopathy. Am J Cardiol 79: 1645, 1997

11) Szabo BM, van Veldhuisen DJ, van der Veer N, Brouwer J, De Graeff PA, Crijns HJ: Prognostic value of heart rate variability in chronic congestive heart failure secondary to idiopathic or ischemic dilated cardiomyopathy. Am J Cardiol 79: 978, 1997

12) James Nolan, Phillip D Batin, Richard Andrews, Sterven J Lindsay, Paul Brooksby, Michael Mullen, Wazir Baing, Andrew D Flapan, Alan Cowley, Robin J Prescott, James M. M. Neilson, Keith AA Fox: Prospective study of heart rate variability and mortality in chronic heart failure. Result of United Kingdom Heart Failure Evaluation and Assessment of Risk Trial (UK-Heart). Circulation 98: 1550, 1998

13) Fauchier L, Babuty D, Cosnay P, Autret ML, Fauchier JP: Heart rate variability in idiopathic dilated cardiomyopathy: Characteristics and prognostic value. J Am Coll Cardiol 30: 1009, 1997

14) Yi G, Goldman JH, Keeling PJ, Reardon M, McKenna WJ, Malik M: Heart rate variability in idiopathic dilated cardiomyopathy: Relation to disease severity and prognosis. Heart 77: 108, 1997

15) Hoffmann J, Grimm W, Menz V, Knop U, Maisch B: Heart rate variability and major arrhythmic events in patients with idiopathic dilated cardiomyopathy. Pacing Clin Electrophysiol 19: 1841, 1996

16）斎藤靖浩, 鼠尾祥三，江幡 淳，泉 礼司，井上省三，寒 川昌信, 河原洋介, 田中淳二, 神山憲王, 末綱竜士, 沢山俊民：拡張型心筋症の心電図所見と予後. 心臓 $31 ： 13,1999$

17) Vanoli E, De Ferrari GM, Stramba Badiale M, Hull SS Jr, Foreman RD, Schwartz PJ: Vagal stimulation and prevention of sudden death in conscious dogs with a healed myocardial infarction. Circ Res 68: 1471, 1991

18) Madwed JB, Albrecht P, Mark RG, Cohen RJ: Low frequency oscillation in arterial pressure and heart rate; A simple computer model. Am J Physiol 256: H1573, 1991

19) Saul JP, Arai Y, Berger RD, Lilly LS, Colucci WS, Cohen RJ: Assessment of autonomic regulation in chronic congestive heart failure by heart rate spectral analysis. Am J Cardiol 61: 1292, 1988

20）井上省三, 鼠尾祥三, 田中淳二, 神山憲王, 斎藤靖浩, 末網竜士, 河原洋介, 寒川昌信, 沢山俊民 : 自律神経 活動の概日リズムよりみた突然死 2 例の検討。心臓 29 (Suppl 5) : 80, 1997

21) Hofmann T, Meinertz T, Kasper W, Geibel A, Zehender M, Hohnloser S, Stienen U, Treese N, Just $\mathrm{H}$ : Mode of death in dilated cardiomyopathy: A multivariate analysis of prognostic determints. Am Heart J 116: 1455, 1988

22) Fuster V, Gersh BJ, Giuliani ER, Tajik AJ, Brandenburg RO, Frye RL: The natural history of idiopathic dilated cardiomyopathy. Am J Cardiol 47 (3): 525, 1981 